\title{
Qatar is a research bonanza for foreigners
}

$\mathrm{F}$ or Kim Critchley, dean of the University of Calgary's Qatar campus, the biggest advantage to doing research in the tiny Arabian Gulf country is clear: the availability of research funding.

"You have this large funding pool, and less competition to access funds," she says. "Your chance of being funded is much higher than it is in Canada."

While your chance of success at the Canadian Institutes of Health Research might be around $4 \%$, she says her institution's success rate with the Qatar National Research Fund (QNRF) is greater than $20 \%$. And that goes up if you revise and resubmit rejected proposals.

Qatar, the world's richest country on a per capita basis, is pouring money and effort into scientific research, in an attempt to modernize and transition to a knowledge economy when its natural gas wealth inevitably runs out. And the results on the ground are impressive, says Critchley.

"They've put an awful lot of financial resources in. They're bringing in top researchers from all over the world and establishing institutes of research," she says. "I think what's taken 100 years to be done in Canada is being done very quickly here."

Exactly how much the country is spending on research is difficult to pin down. Qatar has pledged to spend 2.8\% of its gross domestic product per year on science and research, which would amount to nearly US\$6 billion in funding. But only a fraction of that is actually being spent, because there aren't enough scientists to give it to. The Qatari government does not provide details on how much research funding is actually awarded, or how it breaks down between disciplines.

Health and life sciences research is one of the country's four scientific priorities, set out by the Qatar Foundation for Education, Science and Community Development, the semi-private organization that both drew up the national

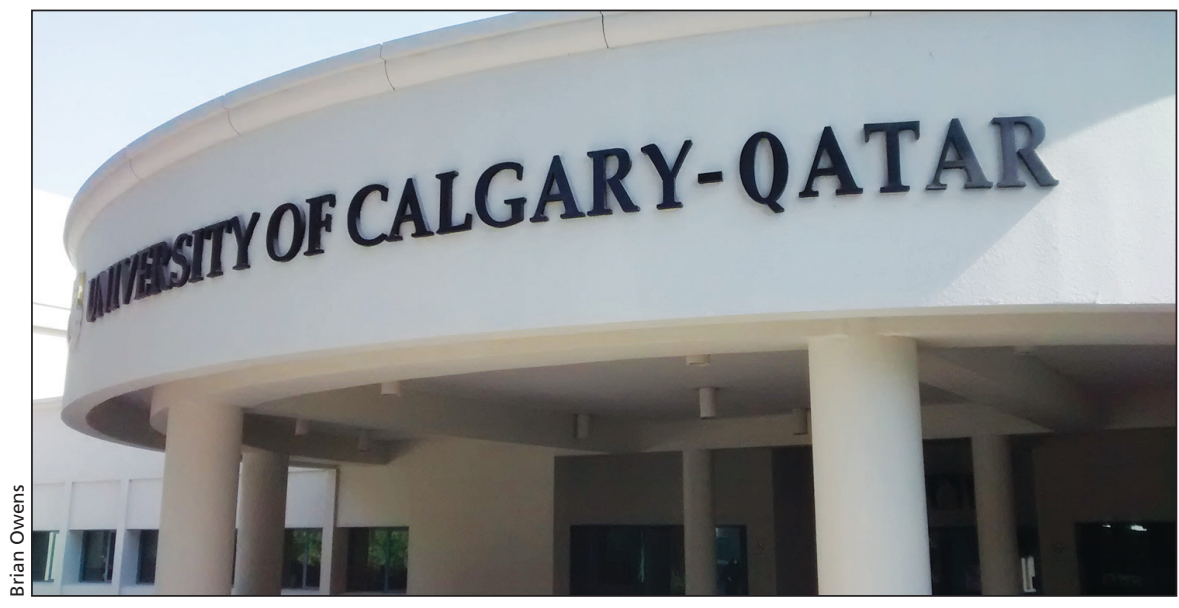

Qatar's heavy investment in medical research is attracting Canadians.

science strategy and controls the purse strings for research through the QNRF and its research institutes.

Thomas Zacharia, the foundation's senior vice-president for research and development, says the key areas of focus in health research are issues that are relevant to and prevalent in the region. That means diabetes, hypertension and cancer are top priorities, as is developing technologies and treatments for personalized medicine.

Calgary is well placed to help out with those goals. In 2007, the university was chosen by the Qatari government to set up a campus dedicated to nursing education. It now has more than 500 undergraduate and master students, and is expanding the number and variety of programs it offers, particularly at the graduate level.

But like its parent institution in Calgary, the Qatar campus is also focused on research, chiefly around health and wellness, or wellness promotion, says Critchley. The campus is working on projects on breast cancer screening, and physical activity and health, specifically looking at why Qatari nationals and long-term residents aren't active. Another area of focus is interprofessional education, seeing how to bring professions together to educate or practise together.

That kind of interdisciplinary work is one area where Qatar needs to improve, she says. For example, the push for genetic testing and personalized medicine will require health professions other than medicine to make it work, including genetic counsellors and nurses to manage the patients after their results come back. "This interdisciplinary approach is somewhat new to the country," she says.

The University of Calgary's Qatar campus has a research grant from Qatar's Academic Health System, a committee set up to promote interdisciplinary work in the country. And Critchley says the campus' researchers have good relationships with branch campuses of other institutions that have an interest in biomedicine - including Weill Cornell Medical College and Newfoundland's College of the North Atlantic. They also work closely with the two domestic universities: Qatar University and Hamad bin Khalifa University. "Because we're small and there's only so many institutions, the key people can drive this interprofessional practice," she says. "All you need is a few champions and it can work." - Brian Owens, Doha, Qatar

\section{CMAJ 2015. DOI:10.1503/cmaj.109-4956}

Editor's note: The Qatar Foundation for Education, Science and Community Development provided the reporter with a travel grant to attend the conference. 